\title{
REFLEXÕES TEÓRICAS SOBRE OS ESTUDOS CULTURAIS NA PÓS- MODERNIDADE E A (DES)CONSTRUÇÃO DE IDENTIDADE(S): BREVE LEITURAS
}

\author{
THEORETICAL REFLECTIONS ON CULTURAL STUDIES IN POST-MODERNITY \\ AND THE (UN)CONSTRUCTION OF IDENTITY(IES): BRIEF READINGS
}

\section{Helder Souza da Silva ${ }^{1}$}

RESUMO: A ideia de escrever esse ensaio partiu da disciplina intitulada "tópicos avançados em cultura" que acontece no Mestrado de Ciências Humanas e Sociais da UFOB. As leituras sobre a "virada cultural", como define Stuart Hall em uma das suas analises dos Estudos Culturais, me fez notar que a cultura não obtinha espaço de averiguação na formação das pessoas na Modernidade, contudo, foi centralizando esse lugar na Pós-Modernidade. As pessoas eram vistas como "indivíduos", padronizados, únicos e imutáveis, construídos para respeitarem um padrão imposto de ideologia hegemônica e perfeita do que se pode ser considerado um ser humano. Porém, com os avanços culturais e produção epistemológicas a partir disso, a cultura é sim, balizadora e embrionária no quesito "formação", ou seja, identidades partem a partir dela. Dessa maneira, na sociedade atual não se pode ignorar como no passado a importância da cultura na formação dos sujeitos e sujeitas, bem como, esses estudos culturais ultrapassaram muros e, consequentemente, um terceiro lugar, de transformação, criação, ganha o seu espaço de direito, pois são neles que outras identidades são construídas capazes de mudarem uma trajetória estruturalista do pensamento.

Palavras-Chaves: Identidade. Cultura. Modernidade. Pós-Modernidade. Virada Cultural.

ABSTRACT: The idea of writing this essay came from the discipline entitled "advanced topics in culture" which takes place in the Master's Degree in Human and Social Sciences at UFOB. The readings about the "cultural turn", as Stuart Hall defines it in one of his analyses of Cultural Studies, made me realize that culture did not have an investigative space in the formation of people in Modernity, however, it was centralizing this place in post-Modernity. People were seen as "individuals", standardized, unique and unchangeable, built to respect an imposed standard of hegemonic and perfect ideology of what can be considered a human being. However, with the cultural advances and the epistemological production based on it, culture is indeed a beacon and embryonic in the "formation" issue, that is, identities start from it. In this way, in today's society one cannot ignore, as in the past, the importance of culture in the formation of subjects, as well as, these cultural studies have gone beyond the walls and, consequently, a third place, of transformation, creation, gains its rightful space, because it is in them that other identities are built capable of changing a structuralist trajectory of thought.

Keywords: Identity. Culture. Modernity. Post-Modernity. Cultural Turn.

\footnotetext{
${ }^{\text {I }}$ Mestrando no Programa de Pós-Graduação em Ciências Humanas e Sociais da Universidade Federal do Oeste da Bahia (UFOB). Advogado, especialista em Direito Público e Direito do Consumidor pela Faculdade Legale. Professor da Rede Estadual de Educação da Bahia, lotado no Centro Territorial de Educação Profissional - Bacia do Rio Grande (CETEP-BRG) na cidade de Barreiras- BA. Cursando Licenciatura em Ciências Sociais pela Faculdade IBRA.
} 


\section{INTRODUÇÃO}

Uma coisa é nítida, a identidade se transformou em uns dos enfoques mais importantes das Ciências Humanas e Sociais, uma palavra bastante estudada e que possui uma relevância na sociedade pós-moderna para compreensão de alguns movimentos sociais, bem como, na formação do sujeito. Esse centro da pesquisa ocupado pela identidade, justifica-se em uma ambiguidade da conceituação que ganha um viés de que a identidade se tornou um problema em meio à crise, ao deslocamento, à incerteza.

Dessa forma, existe uma ansiedade em se falar sobre identidade na pósmodernidade e, isso, é um sintoma contemporâneo que vem se alargando entre pesquisadores/as. Entretanto, essa preocupação em estudar a identidade não se residiu no século XX, como assegura Bauman (2005) que as pesquisas em torno da identidade tinham sua objetificação em um plano totalmente filosófico, o que serviria apenas para meditações.

A partir da pós-modernidade surgiram alguns estudos culturais que ampliaram a visão sobre identidade, fazendo uma análise da influência cultural à formação de cada pessoa. Com isso, a definição de identidade adotou analises a partir das moldagens que se pretendente fazer sobre ela, ou seja, alguns autores/as vão usar o caminho da compreensão social e pessoal sobre a identidade e outros, portanto, partem da ideia de identidade a partir de sistemas culturais, como afirma Hall (2006) sendo um conjunto de pertencimentos da realidade, bem como, um contínuo de significados compartilhados.

Nessa perspectiva, esse ensaio científico tem como objetivo trazer uma compreensão e ressonâncias sobre as mudanças estabelecidas aos estudos e conceituação a identidade e, consequentemente, as pesquisas culturais. Assim, faz-se necessário adentrar a esse espaço de discussões teóricas trazendo a influência exercida sob a perspectivas de Stuart Hall, Inês Hennigen, Neuza Maria de Fátima Guareschi, Viviane Castro Comozzato, Veiga-Neto, Carlos Henrique, Maria Lugones, Anibal Quijano e entre outros.

Assim, essa escrita sugere reflexões a respeito da formação de identidades dentro do espaço de discussões dos Estudos Culturais, que outrora eram considerados transgressões e, agora, são lugares de produção de conhecimento e subjetividades na interpelação na formação dos sujeitos. 


\section{ESTUDOS CULTURAIS E UM NOVO OLHAR A (DES)CONTRUÇÃO DE IDENTIDADE NA PÓS-MODERNIDADE}

Para dar início na compreensão de identidade, faz-se necessário enfatizar as contribuições provocadas por Stuart Hall aos estudos culturais. Em um dos seus escritos intitulado "A identidade cultural na pós-modernidade”, Hall (2006) preconiza a identidade como questão central nas teorias sociais. Sua ideologia argumentativa, é que a velha conceituação de identidade, caraterizada por ser fixa, autocentrada e imutável, e por um segmento abstrato, adentrou em um processo de crise derivada pelos deslocamentos que passou a sociedade moderna.

Segundo Hall (2006) destaca-se três concepções de identidade, quais sejam, o sujeito do iluminismo, o sujeito sociológico, e o sujeito pós-moderno. Assim, o primeiro era caracterizado como um ser humano em unidade, ou seja, nascido com uma identidade que se desenvolvia com passar dos anos, porém, esse indivíduo permanecia estático, sempre o mesmo, idêntico. Aqui, vale ressaltar a crítica realizada por Hall (2006), que essa abstração do sujeito residia na prática ao homem, branco, ocidental. A construção do sujeito sociológico surgiu conjuntamente à complexidade do mundo moderno e graças as suas modificações. Desse modo, esse sujeito passar a ser visto nas interrelações com outras pessoas e agora, com cultura que o permeia. Reconhecia-se ainda, nesse sujeito, a existência de um núcleo, internamente como uma essência, passível de ser modificada com a interação com o mundo e outras identidades.

Já o terceiro sujeito, ou seja, o pós-moderno, por sua vez, rejeita é um ato negacionista as conceituações anteriores e, em uma transformação/desconstrução radical, deixa de ser unificado, estático, imóvel, definições realizadas quer seja sociologicamente ou de forma antológica, passa agora, ao estágio da fragmentação e à noção de que o sujeito é composto por diversas identidades contraditórias e não resolvidas, sendo produtos emergentes de identificações contingentes. (HALL, 2006)

De acordo, com as reflexões do autor, os elementos responsáveis por projetarem por muito tempo nossas identidades culturais tornam-se, também, provisórios, assim, descreve

A identidade torna-se uma "celebração móvel": formada transformada continuamente em relação às formas pelas quais somos representados ou interpelados nos sistemas culturais que nos rodeiam (Hall, 1987). E definida historicamente, e não biologicamente. $\mathrm{O}$ sujeito assume identidades diferentes em diferentes momentos, identidades que não são unificadas ao redor de um "eu" 
coerente. Dentro de nós há identidades contraditórias, empurrando em diferentes direções, de tal modo que nossas identificações estão sendo continuamente deslocadas. (HALL, 2006, p. II-I2)

Diante dessa acepção de fragmentação do sujeito pós-moderno, defendida por Hall (2006) é a mesma compreendia por Bauman (2005) instruindo que, na pré-modernidade, a identidade tinha determinação pelo emergir de escassas oportunidades de elucidações, ou melhor, de ser mais decifrada, não se podia fazer questionamentos do modo "que sou eu, a quais grupos sou pertencentes”.

Assim, Bauman (2005) enfatiza que a questão de se discutir identidade tornou-se relevante e atual. $\mathrm{Na}$ concepção do autor, é proveitosa e necessária, só que, por diversas vezes, equivocada, quando tentam definir identidade sob um imaginário de respostas definitivas e tranquilizadoras. De maneira contumaz, Bauman (2005) erradia seu pensamento para trazer uma explicação, que ao meu ver, parecer ser tão óbvia para mim, contudo, outros/as se perdem, justamente na tentativa de desejar uma fossilização da identidade como sendo algo imutável, ou seja, usando de uma analogia bem pratica, não se pode conceituar identidade hoje como sendo um quadro, em que o pintor ao elaborar os traços com diversas cores, chega ao final da sua obra, modulando-a e fixando em uma parede para ser admirada por apreciadores/as de artes.

Reafirmando o que pensa Hall (2006) e Bauman (2005) a identidade é uma temática intangível, incorpórea, e apropriando da conceituação criada por Bauman (2005) em tratar a sociedade pós-moderna como modernidade liquida, percebe-se, que identidades aparentemente sólidas, como raça, classe social, sexo, gênero, a todo momento são questionadas, revisadas, sobrepostas, fundidas, combinadas.

Assim, pensar nas identidades de outrora, fixas, definidas, recortadas e desprovidas de ambiguidade, me parece não satisfazer os anseios dessa sociedade, o que de outra forma nos capacita a buscar "identidades em movimento-lutando para nos juntarmos aos grupos igualmente móveis e velozes que procuramos, construímos e tentamos manter vivos por um momento, mas não por muito tempo”. (BAUMAN, 2005, p. 32)

Ademais, e para enriquecimento das reflexões aludidas por Hall (2006) elucida que, a modernidade tornou-se um processo de rupturas e, chama bastante atenção para globalização, que para ele, não é um evento que reside na pós-modernidade e, sim, mais antigo do que parece, ou seja, tendo seu inicio exatamente na modernidade a partir do 
século $\mathrm{XV}$, por meio das grandes navegações e, que tinha como finalidade a descobertas de novos territórios.

A inovação para o autor, é que a identidade se transformou em algo contemporâneo politizado. Não é à toa, que ele, considera que o sujeito dessa modernidade tardia - outro nome para pós-modernidade, vem convivendo com uma "crise de identidade". O soar da fragmentação no cotidiano do sujeito, insere-se no que ele determina como "paisagens culturais”, ou seja, de classe, etnia, religiosidade, idioma, sexualidade, nacionalidade e gênero. (HALL, 2006)

Através desse pensamento esclarece que, com os avanços sociais e, consequentemente, com as transformações que isso proporciona, as pessoas não serão mais as mesmas, o que era aparentemente fácil de identificar como identidade genuína, hoje adentra em um oceano de complexidade, justamente, por condicionarem as pessoas em uma gama de identidades, intimamente ligados à sociedade e a cultura.

Segundo Hall (2006) traçar um mapeamento do sujeito moderno é uma tarefa complexa, sendo que, há um deslocamento específico pela substituição do pensamento tradicional, isso explica o deslocamento do sujeito, quando ele enfatiza a teoria marxista, pela descoberta do inconsciente, por meio de Freud, na descoberta da língua como algo anterior a própria existência humana, por meio de Saussure, e o impacto causado pelo feminismo, bem como, os estudos de Foucault na ênfase do poder disciplinar exercida pelo Estado que regula os corpos. Diante desses acontecimentos, ocorre o que Hall (2006) pensa sobre os deslocamentos que esse sujeito moderno enfrenta.

Ainda, analisando essa que podemos chamar de nova(s) construção(ões) de identidade(s) pós-moderna como o título desse ensaio sugere, Stuart Hall (1997) em mais um dos seus escritos intitulado "A centralidade da cultura: notas sobre as revoluções culturais do nosso tempo", o autor nos demonstra que a cultura exerce agora, uma centralidade pós-central, isto é, os discursos outrora ignorados na modernidade de que a cultura tinha uma participação na formação do sujeito, passam a ser aceitos, compreendidos nas reflexões na maneira de produzir subjetivações e participação ativa na construção de identidades.

Nesse sentido, Hall (1997) volta o seu olhar e faz um diagnóstico sobre o lugar da cultura em termos globais e define o que chamou de revolução cultural, intercalando o 
domínio social da cultura na sociedade pós-moderna, por meio do crescimento da indústria cultural através das tecnologias e da revolução da informação.

Na Modernidade o "sujeito", conforme Hall (2006), era senhor de si mesmo, com suas pedagogias centradas e fixas, não se pensava nesse "outro" espaço e, nem que a cultura o influenciava como uma forma de pedagogia da época, o sujeito que hoje se define dentro de uma pluralidade cultural, antes era tido como indivíduo, justamente por se adequar a sua formação individualista e estática.

Atrelado a esse pensamento, acredito que, essa nova perspectiva de se pensar a "cultura", um pensamento paradoxal para sociedade, ou seja, em um só tempo nossa percepção nos condiciona a pensar sobre temas em construção de limites, porém, condiciona-se, também, a pensar um terceiro espaço, um espaço outro, um "pular as fronteiras".

Com isso, existe a possibilidade de se estudar mais ainda sobre as diferenças consolidadas pelas culturas, principalmente, quando se pensar na velocidade em que informações são passadas na atualidade através da internet, onde os sujeitos estão conectados em uma rede mundial de interações. Isso possibilita fazer sínteses de embates entre o considerado antigo e o novo. Hall (1997) ainda, rebate alguns pensadores que pregam sobre o risco de se atingir em pouco espaço de tempo uma cultura uma, em definições globais.

Esse pensamento para Hall (1997) não faz o maior sentido, uma vez que, as transformações culturais globais podem ocorrer a todo instante, porém, o sujeito é extremamente afetado diariamente interpelado pelo processo de desenvolvimento das comunicações e, como essa invasão da revolução cultural nós mudamos o nosso modo de agir e pensar.

Dessa maneira, o autor argumenta que a substantividade se aproxima da subjetividade e a objetividade, em se tratando das questões culturais. Segundo Hall (1997) a formação das nossas identidades existe de uma conexão cultural, isto é, perpassa por uma escolha de cada um, mas em contrapartida, recebe influência das mediações de aspectos objetivos que estão presentes nas leis, nas instituições, nas atividades, enfim, em estruturas construídas e contextualizadas em determinado tempo e lugar. 
Porém, é importante sinalizar como aponta Hennigen e Guareschi (2006, p. 66) trazendo os pensamentos de Bernardes e Hoenisch, "que identidade e subjetividade não são correlatas, mas podem ser articuladas sob certas condições". Ou seja, a conceituação criada de subjetividade no pós-estruturalismo, vai de encontro aquelas definições forjadas da modernidade. Aqui, a identidade percorria um caminho fixo, permanente, até poderia pensar em algumas transformações, mas não muito significativas para compreender o sujeito como derivados de práticas sociais.

O pós-estruturalismo vai erradicar o sujeito descentrado desse ideal em uma caixinha de regras únicas, e fazê-lo caminhar por conceituação de práticas de significações, pois o mesmo recebe carga cultural, política, econômica e, assim, ocorreu essa virada linguística do sujeito, que não se pode modela-lo em algo pronto, parado, como uma estátua e, sim, “está sempre por se fazer”. (HENNIGEN; GUARAESCHI, 2006, p. 66)

Por outro lado, Hall (1997) sustenta a centralidade epistemológica como uma virada cultural e frisa a sua origem na modificação de atitudes em relação a maneira como deve-se encarar a linguagem. Assim, uma nova análise da linguagem serve para uma compreensão da vida social, ou melhor, da realidade.

Frisa-se que, o autor não quer colocar a cultura como algo que esteja acima da de dimensões políticas e econômicas, sobretudo, explica que ela permeia, se encontra inserida nesses campos a todo momento, bem como, a cultura sofre restrições destes campos.

Nesse exato momento, percebemos que a influência da cultura repercute na transformação do conhecimento e na maneira de um novo pensar e conhecer das subjetividades. Essa virada cultura reside nas dimensões culturais, não de maneira isolada, mas um compreender das práticas que constitui os significados que maquiam a subjetividade.

Segundo Hennigen e Guareschi (2006) para entendermos esse momento de mudanças, faz-se necessário analisar também uma outra virada, que seria a "linguística". A linguagem nesse novo cenário ganha uma conotação revolucionária, ou seja, sai da esfera da estruturação e, adentra, ao contexto da vivencia social. Assim, define as autoras "a linguagem deixa de ser vista como mera ferramenta para expressar o que está dado no mundo, para relatar com neutralidade os significados possuídos pelas coisas”. (p. 57) 
Seguindo de uma praxe para designar que são culturas, os seres humanos criam e utilizam de sistemas e códigos para definir, interpretar e padronizar condutas, com objetivo de dar sentido as próprias razões e ações. Nessa perspectiva, entende-se que as práticas sociais para serem instaladas são dependentes de significados, que por sua vez, funcionam e desenvolve seus efeitos através inseridos no discurso, tornando-se discursivas. (HENNIGEN; GUARAESCHI, 2006)

Para Hall (I997, p. 29) “o termo refere-se tanto à produção de conhecimento através da linguagem e da representação, quanto ao modo como o conhecimento é institucionalizado, modelando práticas sociais e pondo novas práticas em funcionamento".

\section{PEDAGOGIAS DO PRESENTE E OS ESTUDOS CULTURIAS: ESPAÇOS FORMADORES DE IDENTIDADES CONTRA-HEGÊMONICAS E (DES)PADRONIZADAS}

Com essas mudanças e transformações socioculturais, não se pode delinear o sujeito na análise da pedagogia dentro de uma caixinha, ou algo, totalmente fechado e, sim, das pedagogias com um aprimoramento das ressonâncias, transformações, interpelações e etc.

Isso, nos leva a sair da padronização única do pensamento em compreender que são inúmeras pedagogias que influenciam e formam o sujeito. Portanto, nota-se uma adjetivação das pedagogias, ou seja, existe hoje as pedagogias tecnicistas, críticas, póscrítica, construtiva, libertária e dentre outras. Assim, a ideia de que a educação pode ser construída em vários espaços agregando aos referenciais teóricos da cultura, possibilitando essa análise da pedagogia de interiorização para a cultura.

Diante desse contexto, passo agora, a analisar as indagações e pensamentos de Viviane Castro Camozzato no seu artigo intitulado "Pedagogias do Presente". A autora de forma objetiva, esclarecedora e, com uma escrita fluida, nos traz reflexões como essa(s) pedagogia(s) do presente são denominadas e a influência pelas discussões do passado que vem sofrendo transformações constantes interferindo na produção de tipos de sujeitos e suas subjetividades.

Esses novos espaços, podem ser entendidos como formadores de identidades, ou seja, aquilo que outrora era expelido como negativo, transgressor, ruim, passou-se, a ser reconhecido como algo fornecedor de "cultura", não aceitando mais algo único como pedra angular na arquitetura dos sujeitos. O pensar ficou diferente e se faz diferente, diferente 
antes traduzido e forjado a ser algo "pecaminoso", sobretudo, agora algo essencial de um novo olhar cultural nessa produção de conhecimento.

Nessa visão e o que se propõe Comazzato (2014) e Bauman (2010) é que a pedagogia do presente nos coloca em um lugar de intérprete e, não mais sobre as subjugações da pedagogia alicerçada no papel do legislador, não se permite mais se acreditar em verdades universais, consequentemente, hoje temos uma multiplicidade de conceitos que nos leva a outras dimensões intelectuais.

Dessa maneira, Comazzatto (2014) entende que em uma sociedade plural, em que as lutas pela significação são praticamente infindáveis na sociedade, a pedagogia precisa trabalhar como aliada na busca de traduzir as culturas para poder compreender e, fazer-se interagir sobre essa pluralidade evidente, como pondera Veiga-Neto (2003, p. 5) alinhado com a construção de Hall (1997) quando escreve "em qualquer caso, parece crescer a centralidade da cultura para pensar o mundo". Ademais, articula a autora com os ensinamentos de Marisa Vorraber Costa sob o viés de amplitude e dimensões que a cultura passa a exercer, sendo assim, ela deixa "de ser domínio exclusivo da erudição, da tradição literária e artística, de padrões estéticos elitizados, e passa a contemplar, também, o gosto das multidões" (p. 585)

Com essas mudanças e transformações socioculturais, não se pode delinear o sujeito na análise da pedagogia na caixinha, ou algo, totalmente fechado e, sim, das pedagogias com um aprimoramento das ressonâncias, transformações, interpelações e etc. Isso, nos leva a sair da padronização única do pensamento em compreender que são inúmeras pedagogias que influenciam e formam o sujeito. Portanto, nota-se uma adjetivação das pedagogias, ou seja, existe hoje as pedagogias tecnicistas, críticas, pós-crítica, construtiva, libertária e dentre outras. Assim, a ideia de que a educação pode ser construída em vários espaços agregou aos referenciais teóricos da cultura, possibilitando essa análise da pedagogia de interiorização para a cultura.

Há uma articulação entre a pedagogia(s) e a(s) cultura(s) de forma incessante que na compreensão de Comozzato (2014, p. 580) "parece admissível situar o conceito de pedagogias culturais como a expressão de um conjunto de transformações sociais e culturais que tornaram possíveis a sua emergência”. Ou seja, os estudos culturais se dão em torno das redes de saberes na contemporaneidade e, não ficando adstritos à escola. No 
senso comum, associar pedagogia como instrumento escolar e, unicamente, a setores educacionais cria-se o hábito do pertencimento, ou seja, pensa-se que a escola tem o saberpoder centralizador na construção do sujeito alinhado com as produções pedagógicas praticadas nesse ambiente.

Partindo desse pressuposto, configurou-se a escola com responsabilidade para representação do sujeito e, ademais, o conhecimento produzido unificaria ao surgimento da imagem do cidadão ideal.

De certo, que esse pensamento alienador de pedagogia não contempla mais os anseios da sociedade, portanto, a autora é bem incisiva que a sua intenção não um contar sobre a historicidade da pedagogia, sobretudo, cada sujeito se desfazer das amarras e "mostrar que o conceito de pedagogia continua, proximamente a nós, sofrendo transformações nesse tempo em que está operando”. (p. 579)

Esse espaço, que podemos até chamar de novo em uma perspectiva reconstrutiva do saber, do ser, do permanecer, um lugar que ecoa reexistências e insurgências, que o conceito de produção de conhecimento ultrapassa os muros do que se entende como "padrão" dentro de uma sociedade.

Essa padronização do conhecimento, engessa a ideia da colonização nos dias de hoje, porque se torna comum pensar que a criação/surgimento do conhecimento e sua análise científica, social, cultural e dentre outros ramos epistemológico residem apenas em escolas, laboratórios, universidades, faculdades e etc.

Por isso, uma postura decolonia/pós-colonial tem como finalidade reagir aos efeitos da colonialidade no presente implantando, inclusive, os procedimentos metodológicos que são marcadores dos modos de se pesquisar. Dessa maneira, no mundo ocidental, a relação viável de se estabelecer com processos de conhecimento é através de marcas seguindo a lógica colonial que perseguem os estilos de reconhecer, aprender e reproduzir saberes.

Ocorre que, existem outros espaços que os saberes subalternizados são imbuídos de posicionamento crítico, transformações e representações, como é o caso do Slam Poetry. Nesse sentido, explica Freitas (2020) que é um termo americano que designa batalhas de poesias, organizadas em lugares de fácil acesso ao público. Os poemas apresentados devem ser autorais, com duração de três minutos, não podendo utilizar adereços, músicas e o público é o avaliador. Por ser algo autoral, comumente, as discussões apontam 
problemáticas sociais, políticas, quase que uma autobiografia, isso vai depender do/da poeta na declamação e, a plateia acaba se identificando com as performasses.

As temáticas dessas performasse são variadas, dentro de uma narrativa de primeira pessoa, colocando a experiência de vida dos/das poetas sempre latentes nas estrofes, assim, são traços que recebe o nome de "autorrepresentação". (D’ALVA, 2oII apud FREITAS, 2020).

Segundo Freitas (2020, p. 5) "ao relatar casos vividos por ele/as, os/as poetas expõem a lógica do funcionamento dos mecanismos de controle biopolítico e enunciam os limites da democracia dentro da sociedade brasileira cordial".

Percebo que nesse momento da performasse o sujeito de liberta do seu "eu" fechado dentro de uma estrutura pré-estabelecida, o palco algo se torna o momento de se reproduzir e produzir conhecimento, um saber de cunho encorajador e visível ao mesmo tempo. Atento-me que o slam não é só uma nova arte de performace e, sim, um ambiente de representações, em que seus poemas e corpos, exibem as marcas dos processos de subjetivação ao quais estão submetidos/das cotidianamente que leva o público a refletir.

Para além da competição, são espaços de debates, união, fortalecimento, reflexividade, reconhecimentos de identidade e diferenças, recebendo destaque por suas poesias marginais. O slam transita entre essa disputa entre o que é cultural, por não ser um movimento institucionalizado e, ao mesmo tempo, não é criminalizado, sobretudo, carrega o estigma da marginalidade, mas traz ressignificação também, pois as poesias se revestem de subjetividades dos/das poetas, em suas diferentes realidades sociais, raciais, de gênero, sexualidade e econômica.

Nesse caminho de visibilidade e reexistência, atento-me aos ensinamentos de María Lugones, uma filosofa feminista nascida na Argentina, que diante da sua pesquisa seguiu por analisar e compreender diversas formas de resistências e diversas opressões. Essa brilhante mulher, fica responsável pela apreciação do feminismo decolonial, onde cunhou o termo "colonialidade de gênero", por meio do que sedimenta ser o gênero uma das configurações de imposição colonial.

Ao ler sua obra intitula de "Rumo a um feminismo decolonial" concentro-me em compreender como a autora como em um ato de abrir uma cortina logo pela manhã para 
que os raios solares adentrem em uma casa, nos faz entender que a colonialidade de gênero anda de mãos dadas com a "colonialidade do poder", conceito traçado por Quijano (2005).

A ideia de "raça" como analisa Quijano (2005) nos processos de colonialidade imposta no mundo a fora, fez com que se legitima-se às relações de dominação. Certamente, o continente Europeu como centro iluminador do poder foi um viés importante na elaboração do ideal propagador e única configuração de formação do conhecimento, ademais, o surgimento e construção acerca de questões sobre as raças no período colonial.

Outrossim, o critério de raça foi compreendido como primeiro gestor para rotular e fazer uma distribuição das populações em diversos espaços políticos, sociais, culturais e econômicos tudo isso inserido dentro da modernidade e contemporaneidade das sociedades.

Portanto, segundo Quijano (2005) os impactos do processo colonial foi calcando através do tempo e espaço, onde América Latina e a África foram suas maiores vítimas. Essas estruturas coloniais foram culpadas por disseminarem as discriminações sociais, com isso, cria-se as construções intersubjetivas, mais um material fruto da dominação eurocêntrica perpassado como algo naturalizado e não um movimento de conflitos e derramamento de sague para imposição de um poder.

Diante da compreensão desse cenário sobre as relações de poder e, obviamente, as histórias vivenciadas pelos países que sofreram com a colonização, especialmente esse corte para as nações inseridas na América Latina, como entende Lugones (2014, p. 936) "Eu compreendo a hierarquia dicotômica entre o humano e o não humano como a dicotomia central da modernidade colonial”.

Percebe-se, que se apropriando da tese criada por Quijano, a autora nota que a colonialidade do poder perfaz em critérios político, social, cultural e econômico, se faz presente também, no gênero, ampliando os horizontes desse processo de colonização, identificando que não se restringia apenas ao saber, ao poder e ao ser.

Nessa concepção, Lugones (2014) compreende que, a partir do processo colonial, fêmeas e machos foram marcados com a classificação de mulheres e homens e etnias, sendo está com as rotulagens enquanto raças, ou seja, brancos, negros e etc. Assim, houve a inferiorização e a superioridade fixada conforme a padronização europeia, sobretudo, a 
mulher negra foi estigmatizada e inferiorizada de uma forma mais árdua, pode-se considerar uma dupla forma negativa de subordinação, por ser mulher e negra.

Centrando na percepção de Lugones (2014), através da sua análise e, uma somatória em sua tese para um feminismo decolonial, concretiza que mulheres, enfatizando, não brancas, que sofreram a cólera do processo colonial, foram postas em um nível de subalternização tão elevado, não fazendo parte de um discurso feministas eurocentrado.

É sabido por meio de Quijano (2005) e Mignolo (2005) que a modernidade criou tendências sistemáticas para se classificar a humanidade em seguimentos fechados e universalistas. Assim, negro(a), mulher, índio, gay, latino, fixam na ideia de termos homogêneos, ocasionando, um apagamento das individualidades para se chegar em algo uniforme e indistinto. Nota-se que as subjetividades recebem uma carga de sufocamento com o objetivo de retirar direitos, bem como, do não reconhecimento como seres humanos.

Dessa maneira Lugones (2014) analise o sistema colonial de gênero para dar maior visibilidade aos grupos homogeneizados, oferecendo voz ao silêncio da história e reconstruí-los, abrindo assim, fissuras nas teorias levadas na modernidade.

Nessa perspectiva, Quinjano (2005) ensina que o poder da colonialidade é essa rotulação em categorias dos povos, ou seja, a racializações da humanidade, enquanto que, Lugones (2014) expande esse entendimento, concretizando que o processo de colonização reduz ativamente o ser a nada, desumanizando e, colocando esses seres hábeis para receberem uma sistematização, uma sujeição, concedendo ao colinzado/a status de nãohumano.

Em consonância a esse pensamento, a autora enfatiza "nenhuma mulher é colonizada, nenhuma fêmea colonizada é mulher”. (LUGONES, 2014, p. 939). Assim, entende-se que o processo de colonizador reduz a mulher a uma categoria vazia e, isso, evidencia-se ainda mais a colonialidade de gênero, pois materializa a mulher colonizada não sendo uma mulher, ou seja, não passa de fêmeas, ausentes da essência de serem consideradas como ser.

Para a autora, essa hierarquia de gênero serviu como fundamento para condenar quem não se enquadrava na superioridade do homem-branco europeu. A mulher era compreendida como oca, um ser, mas nada se igualando ao ser do amago masculino eurocêntrico, eram um objeto opaco, sem luz, não tinha consciência, passivas, quem tinha 
o poder de questionar o seu próprio ser, eram os homens, tachados de unicamente seres pensantes. (LUGONES, 2014)

Com isso, descreve Lugones (2014, p. 937) sobre essa ferramenta de opressões,

\begin{abstract}
As condutas destes colonizados e suas personalidades/almas eram julgadas como bestiais e, portanto, não gendradas, promíscuas, grotescamente sexuais e pecaminosas. Mesmo que nesse tempo a compreensão do sexo fosse dismórfica, os animais eram diferenciados como machos e fêmeas, sendo o macho a perfeição, a fêmea, o inverso e a deformação do macho. Hermafroditas, sodomitas, viragos e os/as colonizados/as, todos eram entendidos como aberrações da perfeição masculina.
\end{abstract}

Vislumbra-se, que essas caracterizações impostas pelos colonizadores arquitetaram também a lógica e pratica das violências coloniais. Segundo a autora "os machos tornaramse não-humanos-por-não-homens, e fêmeas colonizadas tornaram-se não-humanas-pornão-mulheres" (LUGONES, 2014, p. 937).

Portanto, o sexo passa ser um critério importante na rotulação dos/das colonizados/as, justificando assim, os desvaneio violento de interpelação dos corpos. Esse processo baseado em um ideal moderno de civilização não dissipou somente corpos, incluindo memorias, relações subjetivas e intersubjetivas e dentre outras.

Para Lugones (2014) descolonizar gênero é, indubitavelmente, um processo crítico sobre a opressão de gênero enraizado na zona da racialização, capitalista e colonial e heteronormativa, encorajando mulheres a terem noção e consciência de si, trazendo isso como um seguimento de resistência, principalmente, porque essa diferenciação, essa dicotomia e binarismos, renega o conceito de humanidade.

Nesse formato no qual estou escrevendo sobre ressonâncias de insurgências e reexistências, bem como, pensando sobre (re)construção de identidades e produção de novas epstemologias despadronizadas, declino-me agora, a obra de Carlos Henrique Lucas de Lima, com título "Linguagens de Pajubeyras: re(ex)sistência cultural e subversão da heteronormatividade".

Deparo-me que, o autor utiliza de deslocamento epistêmico decolonial para demonstrar através do linguajar pajubeiro usual por populações subalternizadas, como essa linguagem perturba os discursos dominantes, no que se diz respeito a gênero e sexualidade. Ademais, o pajubá, língua ou gíria verbal utilizada por dissidentes sexuais e de gênero no Brasil, que faz um misto com nagô, yorubá dentre outros, contudo, o que Lima (2017) 
coloca como centro de sua pesquisa, não é uma análise enquadra sociolinguística e, sim, o pajubá sendo caráter formado de subjetivação.

Segundo Lima (2017), a linguagem pajubeyra inicia na ditadura militar brasileira e, com a opressão realizada pelos policiais, sobretudo, para afastar pessoas indesejadas, sobretudo, transexuais e travestis, criando-se, assim, uma forma de ato político fundamentado no ideal de perfomatividade da linguagem e um poderio de confusão e resistência.

A analise realizada pelo autor, traz uma construção paralela de impedir o epistemicídio e destruição de pessoas e dos seus saberes, todavia, produz o pajubá. O lema é não descrever somente, mas produzir parcialmente o que descreve. Assim, nos ensinamentos de Lima (2017), o pajubá constrói formas de nomeação que vão além de produzir subjetividades que resistem a hetornormatividade, no entanto, é o surgimento de novas formas de nomear, que anula a eficácia da norma, como podemos aprender com Hall (2006) tratando-se de um processo de reesignificação.

Com isso, acredito que o cerne do livro se trata propriamente de uma obra pajubá, entendo da não vinculação a padronização, de uma única forma de se escrever, referindo-se muitas vezes a termos do pajubá para elevar o pensamento com eles.

De acordo com Lima (2017) se predispõe em sua pesquisa, há não se limitar na ânsia de construção do pajubá com um bloco de palavras quase que incompreensíveis para quem encontra-se fora desse ambiente, todavia, configura-se em um ato de desvinculação dos jugos do conhecimento.

Através de uma escrita perspicaz e, com um humor ácido nas entrelinhas, sem deixar de lado o aprofundamento original sobre a temática somado pela inovação crítica e teórica, descrita no poema Serventia Pajubeyra, como "sambar na cara da sociedade". (LIMA, 2017, p. 156).

Portanto, à medida que nos debruçamos sobre esses textos, tornamo-nos convictos em pensar e repensar os poderes e despoderes suportados por grupos considerados subalternizados na sociedade, mantendo o foco em suas narrativas dicotômicas, ou seja, uma análise que transborda entre a escravização das vivências e as liberdades que revelam os processos de ruptura, a partir dos quais se projetam vozes, vozes essas quem são faladas através de um novo corpo. 
Assim, por meio dessas obras, possamos analisar enquanto pesquisadores/as a realidade social através de outras lentes e, contribuir para reivindicar a dignidade e igualdade desses grupos e fortalecer o processo de apropriação de um lugar.

\section{CONSIDERAÇÕES FINAIS}

Diante das leituras apresentadas, nota-se um verdadeiro ultrapassar de padrões, uma vez que, além da identidade ser moldada na "modernidade" como algo intocável e imutável, onde não se tinha possibilidade de pensar as formações de identidades de outra maneira, senão em uma padronizada, a virada cultura na "pós-modernidade" trouxe, justamente, a cultura como balizadora e integradora na construção de sujeitos e sujeitas.

A sociedade atual não aceita mais ficar em uma caixinha imaginando como será o mundo fora dela, sobretudo, são esses espaços, agora, centros de criação, de conhecimento, de novas experiências, de se fazer a cultura.

Portanto, as pessoas são a todo instante transformadas e, essas transformações nos leva a pensar como os estudos culturais foram capazes de nos guiarem a outra perspectiva de rotular "indivíduos", saindo de um movimento individualista, para "sujeitos", fortemente construídos a partir do local que esteja inserido e, não só por ele, mas como disse, a todo momento, através da linguagem, discurso, escola, televisão, redes sociais e dentre outros.

Essa visão faz com que, espaços-lugares, considerados afastados dos padrões para produzir cultura e conhecimento sejam reconhecidos como um terceiro-espaço, possível, agregador, somatório, na construção de identidades, uma vez que, podem ser consideras novas porque agora são vistas, ter um lugar de voz, são percebidas, porém, antes eram apenas rotuladas, não como essas identidades desejavam ser chamadas, mas como a própria sociedade as padronizava, carregando estigmas, preconceito e exclusão.

Nesse sentido, pensar, produzir, conhecer, as diferentes identidades construídas de mãos dadas com a cultura, nos capacita em enxergar espaços ricos de epstemologias, capazes de alicerçar ideologias transformadoras na nossa formação de caráter e nos identificarmos. 


\section{REFERÊNCIAS}

BAUMAN, Zygmunt. Identidade. Rio de Janeiro: Jorge Zahar, 2005.

BAUMAN, Zygmunt. Legisladores e intérpretes: sobre modernidade, pós-modernidade e intelectuais. Trad. Renato Aguiar. Rio de Janeiro: Jorge Zahar, 20 o.

CAMOZZATO, Viviane Castro. Pedagogia do presente. Educação \& Realidade, Porto Alegre, v. 39, n. 2, p. 573-593, abr./jun. 2014. Disponível em: http://www.ufrgs.br/edu_realidade

FREITAS, Daniela Silva. Slam resistência: poesia, cidadania e insurgência.Rev. de Estudos de Literatura Brasileira Contemporânea. Disponível em: http://www.scielo.br/ Acesso em: 05 mar.2021.

HALL, Stuart. A centralidade da cultura: notas sobre as revoluções culturais do nosso tempo. Educação\& Realidade, Porto Alegre, v. 22, no 2, p. 15-46, jul./dez. 1997 . https://seer.ufrgs.br/index.php/educacaoerealidade/article/view/7136r.

HALL, Stuart. A identidade cultural na pós-modernidade - tradução Tomaz Tadeu da Silva, Guaracira Lopes Louro-II. ed. -Rio de Janeiro: DP\&A, 2006. Disponível no site https://leiaarqueologia.files.wordpress.com/2018/o2/kupdf-com_identidade-cultural-napos-modernidade-stuart-hallpdf.pdf. Acesso em ig de jun. de 2021.

HENNIGEN, Inês; GUARESCHI, Neuza Maria de Fátima. A subjetivação na perspectiva dos estudos culturais e foucaultianos. Psicol. educ., São Paulo , n. 23, p. 57-74, dez. $2006 \quad$ Disponível em 〈http://pepsic.bvsalud.org/scielo.php?script=sci_arttext\&pid=SI4I4$69752006000200004 \& \operatorname{lng}=p t \& n r m=$ iso $>$. acessos em i8 jun. 2021.

LUGONES, Maria. Rumo a um feminismo decolonial. Disponivel em: https://www.scielo.br/scielo Acesso em:05 mar.202I

MIGNOLO, Walter. Novas reflexões sobre a "idéia da América Latina": a direita, a esquerda e a opção descolonial. Disponível em: http://www.scielo.br/sciel. Acesso em II de maio de 2021.

QUIJANO, Aníbal. Colonialidade do poder, eurocentrismo e América Latina. Disponível em: http://biblioteca.clacso.edu.ar/ar/libros/lander/pt/lander.html. Acesso em: in de maio de 202I.

VEIGA-NETO, Alfredo. Cultura, culturas e educação. Revista Brasileira de Educação, no23, mai-ago 2003. Disponível em: https://www.scielo.br/j/rbedu/a/G9PtKyRzPcB6Fhx9jqLLvZc/?format=pdf\&lang=pt. 